\title{
Fault Classification on Transmission Line of 10kV Rural Power Grid
}

\section{Chunyu Lv1 ${ }^{1}$, Shuguang Zhang²}

${ }^{1}$ College of Mechanical and Electric Engineering Agricultural University of Hebei, Baoding, China

\begin{abstract}
This paper proposes a technique using Discrete Wavelet Transform (DWT) and Back-Propagation Neural Network (BPNN) to identify the fault types on transmission line of $10 \mathrm{kv}$ rural power grid. The PSCAD is used to simulate fault signals. The mother wavelet daubechies4 (db4) is employed to decompose high frequency component from these signals. The variations of first scale high frequency component that detect fault are used as an input for the training pattern. The result has shown that the proposed technique gives satisfactory results.
\end{abstract}

Keywords: Discrete Wavelet Transform, Neural Network, Transmission Line, Fault Classification, PSCAD

\section{Introduction}

The fault on transmission line of $10 \mathrm{Kv}$ rural power grid occurred easily because of the extremely badly environment. What worse, with the increasing of transmission line,the regional environment of line is more complex,so that,the difficulty of finding fault become harder and harder ${ }^{[1]}$.In 1980 s, the fault classification techniques based on the variation of three phase voltage and current has been proposed $^{[2]}$.Ten years later,the method of identify fault type using Neural Network or Fuzzy logic attracted many scholars' attention ${ }^{[3-4]}$. At the end of 1990s, the trend of power system signal analysis has been changed and the computional tools with the function of signal processing were widly used.The development in algorithm for detecting transmission line has made progress, meanwhile,promoted the development of transient technology ${ }^{[5]}$. The application of wavelet transform can make the operation of transient protection more effective ${ }^{[6]}$.

The wavelet transform is very effective in detecting transient signal of fault,but it can not completely characterized the fault. To explore a suitable artificial neural network is of great significance in the new development of protection system ${ }^{[7]}$. If the fault types of transmission line can be identified by wavelet transform and BP neural network, this method will be superior.

This paper present a new decision algorithm,which can identify the fault types that apply in the relay protection device.The fault conditions are simulated with PSCAD, In the simulation, we can get the current waveform, and then use the wavelet transform to extract the current waveform. Then,the algorithm is constructed based on BP neural network. The effectiveness of the algorithm through the fault angle, fault location and phase to verify.

\section{Wavelet transform}

The wavelet is a local wave with a mean value of zero and a specific shape and finite time. The advantage of wavelet transform is that the high frequency and low frequency components can be detected by the fine adjustment of the band. The results of wavelet transform are shown in time domain and frequency domain. The scale parameter and the translation parameters of mother wavelet are discrete in the range of analysis, the result as shown in Eq.1.

$$
D W T(a, b)=2^{-\frac{a}{2}} \sum_{k} f(k) \psi\left[b 2^{-a}-k\right]
$$

Where $\psi\left[b 2^{-a}-k\right]$ is mother wavelet.

\section{Simulation}

A sampling rate of $200 \mathrm{KHZ}$ fault signal simulated by PSCAD. The power system model is shown in Figure 1.In the simulation,the fault model is decided by the variation of parameter,the parameters are as fellows:

(1) Fault type:single phase to ground;double line to ground;line to line and three phases fault.

(2) Fault location:vary from $10 \%$ to $90 \%$, with increasing $10 \%$ of transmission line.

(3) Reference phase:phase A

(4) Inception angle:vary from $0^{\circ}$ to $330^{\circ}$, with increasing by $30^{\circ}$

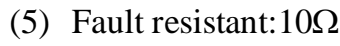

This article is published under the terms of the Creative Commons Attribution License 4.0 Author(s) retain the copyright of this article. Publication rights with Alkhaer Publications.

Published at: http://www.ijsciences.com/pub/issue/2016-01/

DOI: 10.18483/ijSci.894; Online ISSN: 2305-3925; Print ISSN: 2410-4477 


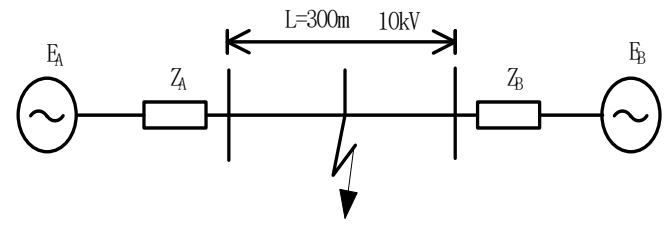

Fig .1 The Pattern of System

The fault signal generated by PSCAD is interfaced to MATLAB,then use the wavelet toolbox to analyze the transient high frequency components. The positive sequence voltage and current and zero sequence voltage and current are calculated by Clark transform matrix.

The fault detecting decision is processed by the positive sequence voltage and current.Then,decompose the high frequency components with mother wavelet db4. These current voltage signals are carried out by discrete wavelet transform, and then the obtained coefficient squares in order to observe the mutation clearly. It can be seen that when the fault occurs, the high frequency component of the coefficient has a significant mutation compared with those before an occurrence of the faults as shown in Fig. 2 and Fig. 3.

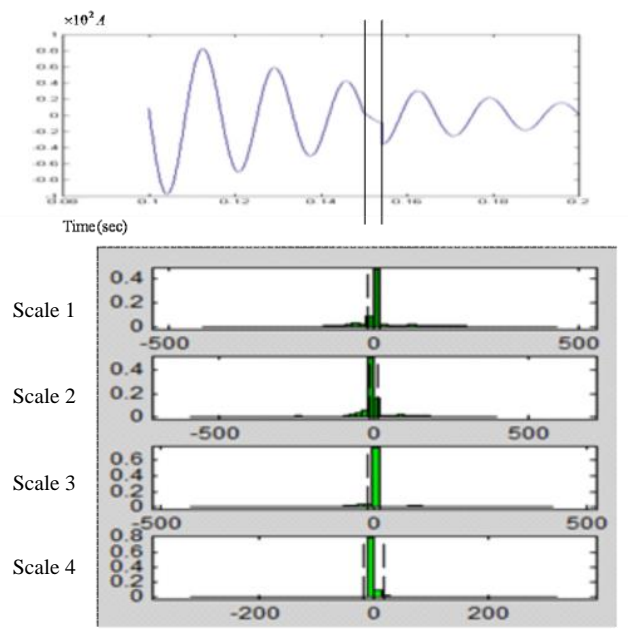

Fig. 2 Wavelet Transform from scale 1 to 4 for Fault Current

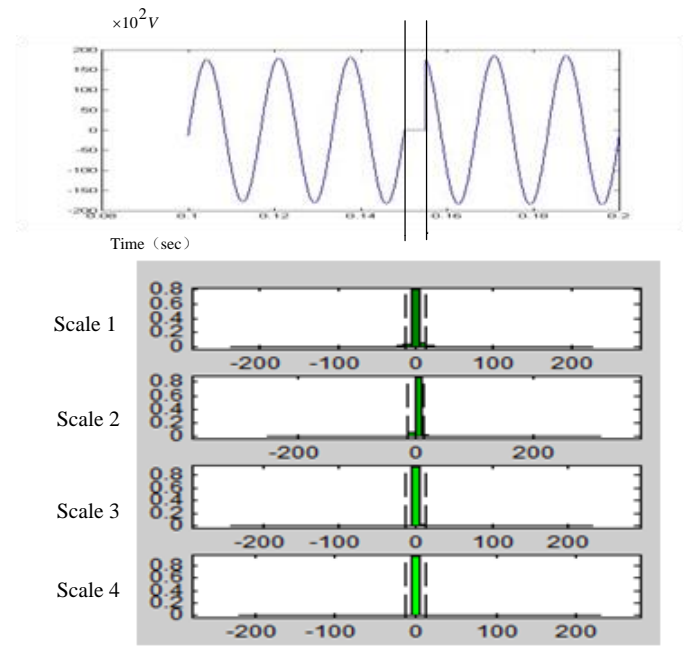

Fig.3 Wavelet Transform from scale 1 to 4 for Fault Voltage

Through a large number of simulation, it can be found that the waveform of the discrete wavelet transform in the scale 1 is sufficient to show that the single circuit transmission line has a fault. Then, there is no need to use a higher level of coefficient in the algorithm, the coefficient in scale 1 from DWT are used in the process of neural network trainning later.

\section{Decision algorithm}

According to the simulated signal, the discrete wavelet transform is used in the $1 / 4$ period of the voltage and current waveform of the fault, and the wavelet transform is used to obtain the coefficient of scale 1 for the training and testing of BP neural network. This paper involves a BP neural network with one input layer, two hidden layers and one output layer. In addition, when the activation function of the output layer is linear function, the activation function of all hidden layers is sigmoid function.

Before the training process, the input data set is standardized, and then the data set is divided into 720 training sets and 360 test sets. Each BP neural network consists of 8 input neurons, 2 hidden layers and 4 output neurons. The input parameters are the maximum of discrete wavelet transform at the A, B, C phase $1 / 4$ and the waveform of zero sequence voltage and current for post fault. the output variables corresponding to, $\mathrm{C}, \mathrm{B}$, and $\mathrm{A}$ are specified as 0 or 1 , as shown in Table 1. If the output value of BP neural network is less than 0.5 , it indicates that there is no fault; if the output value of the BP neural network is more than 0.5 , the fault is indicated. In addition, the number of initial neurons and the number of neurons in the first hidden layer are 8 and 11 respectively.

In the training process, the Levenberg-Marquardt method is used to adjust the weight and the deviation, and then the best value of the average absolute 
percentage error (MAPE) is calculated by the 20000 iteration. Before the training cycle, the number of neurons in the two hidden layers will increase. When the number of neurons in the first hidden layer is reached or when the MAPE of the test set is less than $0.5 \%$, the training process will be over. Table 2 is the results of the training process.

TABLE 1. OUTPUT LOGIC OF BP FOR CLASSIFY FAULT TYPE

\begin{tabular}{|c|c|c|c|c|}
\hline Classify of fault type & $\mathrm{A}$ & $\mathrm{B}$ & $\mathrm{C}$ & G \\
\hline normal & 0 & 0 & 0 & 0 \\
\hline Phase A to ground fault & 1 & 0 & 0 & 1 \\
\hline Phase B to ground fault & 0 & 1 & 0 & 1 \\
\hline Phase $\mathrm{C}$ to ground fault & 0 & 0 & 1 & 1 \\
\hline Phase A、B to ground fault & 1 & 1 & 0 & 1 \\
\hline Phase B、C to ground fault & 0 & 1 & 1 & 1 \\
\hline Phase C、A to ground fault & 1 & 0 & 1 & 1 \\
\hline Phase A to phase B fault & 1 & 1 & 0 & 0 \\
\hline Phase $\mathrm{B}$ to phase $\mathrm{C}$ fault & 0 & 1 & 1 & 0 \\
\hline Phase $\mathrm{C}$ to phase A fault & 1 & 0 & 1 & 0 \\
\hline Three phase fault & 1 & 1 & 1 & 0 \\
\hline
\end{tabular}

TABLE 2. RESULT AND MAPE

\begin{tabular}{ccccc}
\hline $\begin{array}{c}\text { Number neuron in } \\
\text { hidden }\end{array}$ & $8-7$ & $9-8$ & $10-9$ & $11-10$ \\
\hline MAPE of Training & 2.4174 & 0.9732 & 1.8568 & 0.6578 \\
MAPE of Test & 2.6132 & 1.4193 & 1.8291 & 0.9887 \\
$\begin{array}{c}\text { Training time } \\
\text { (minute) }\end{array}$ & 95.8 & 127.5 & 158.3 & 196.2 \\
\hline
\end{tabular}

After the training process, the fault types of transmission lines can be distinguished by this method. In this paper, the case study of the system is shown in Figure 1. The fault types of each position of the system are analyzed. Based on the transmission line on different fault angle and different fault location test, can be found using this algorithm to classify the fault of the accuracy is high.

\section{Conclusions}

In this paper, a method based on discrete wavelet transform and BP neural network to identify the fault types of single circuit transmission line is proposed. As mother wavelet, the DB4 is used to train the BP neural network. The simulation results show that the method is not affected by fault type, fault resistance and fault location with high accuracy and reliability.

\section{References}

1. LI Xiao-song,NI Bin,LI Bin,et al.Analysis on the factors influencing theoretical line loss for rural low-voltage distribution network[J]. Journal of Electric Power Science and Technology,2013,4(11):59-64.

2. W.D. Breingan, M.M Chen and T.F. Gallen.Laboratory Investigation for a Digital System for the Protection of Transmission Lines[J].IEEE Transaction on Power Apparatus and Systems, 1979, 98(2):pp. 350-368.

3. T.Dalstein and B. Kulicke.Neural Network approachto fault classification for high speed protective relaying[J] .IEEE Transaction on Power Delivery,1995,10(2): pp. 1002-1009.

4. A. Ferrero, S. Sangiovanni and E. Zappitelli.A Fuzzy-set approach to fault-type identification in digital relaying[J]. IEEE Transaction on Power Delivery,1995,10(1):pp. 169-175.

5. Ahmad Salehi Dobakhshari, Ali Mohammad Ranjbar. A Wide-Area Scheme for Power System Fault Location Incorporating Bad Data Detection[J]. IEEE Transactions on Power Delivery,2015,30(2):800-807.

6. Papiya Dutta, Ahad Esmaeilian, Mladen Kezunovic.Transmission-Line Fault Analysis Using Synchronized Sampling[J].IEEE Transactions on Power Delivery,2014, 29(2): pp.942-950.

7. P. Makming, S. Bunjongjit, A. Kunakorn, S. Jiriwibhakorn and M.Kando. Fault diagnosis in transmission lines using wavelet transforms[C]. IEEE Transmission and Distribution Conference, Yokohama, Japan,October 2002, pp. 2246-2250 